\title{
NEAR-TERM DEMONSTRATION OF BENIGN, SUSTAINABLE, NUCLEAR POWER
}

\author{
C.E. Walter
}

This article was submitted to

Global Foundation, Inc., "Global Warming \& Energy Policy" Fort Lauderdale, FL, November 26-28, 2000

\section{September 21, 2000}

U.S. Department of Energy

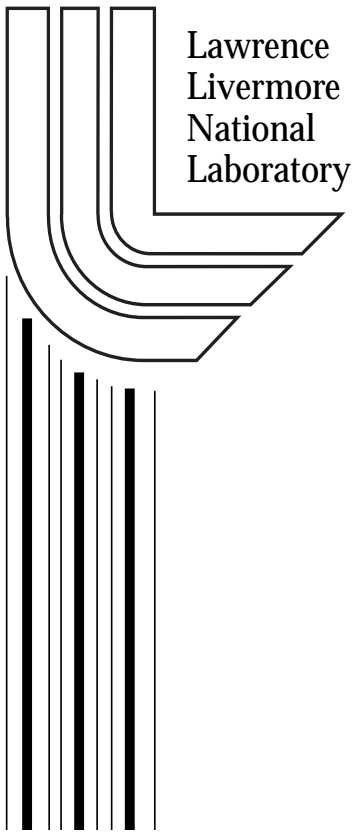




\section{DISCLAIMER}

This document was prepared as an account of work sponsored by an agency of the United States Government. Neither the United States Government nor the University of California nor any of their employees, makes any warranty, express or implied, or assumes any legal liability or responsibility for the accuracy, completeness, or usefulness of any information, apparatus, product, or process disclosed, or represents that its use would not infringe privately owned rights. Reference herein to any specific commercial product, process, or service by trade name, trademark, manufacturer, or otherwise, does not necessarily constitute or imply its endorsement, recommendation, or favoring by the United States Government or the University of California. The views and opinions of authors expressed herein do not necessarily state or reflect those of the United States Government or the University of California, and shall not be used for advertising or product endorsement purposes.

This is a preprint of a paper intended for publication in a journal or proceedings. Since changes may be made before publication, this preprint is made available with the understanding that it will not be cited or reproduced without the permission of the author.

This report has been reproduced directly from the best available copy.

Available to DOE and DOE contractors from the

Office of Scientific and Technical Information

P.O. Box 62, Oak Ridge, TN 37831

Prices available from (423) 576-8401

http:/ / apollo.osti.gov/bridge/

Available to the public from the National Technical Information Service

U.S. Department of Commerce 5285 Port Royal Rd., Springfield, VA 22161 http://www.ntis.gov/

OR

Lawrence Livermore National Laboratory Technical Information Department's Digital Library http://www.llnl.gov/tid/Library.html 


\title{
NEAR-TERM DEMONSTRATION OF BENIGN, SUSTAINABLE, NUCLEAR POWER
}

\author{
Carl E. Walter*
}

Nuclear power reactors have been studied, researched, developed, constructed, demonstrated, deployed, operated, reviewed, discussed, praised and maligned in the United States for over half a century. These activities now transcend our national borders and nuclear power reactors are in commercial use by many nations. Throughout the world, many have been built, some have been shut down, and new ones are coming on line. Almost one-fifth of the world's electricity in 1997 was produced from these reactors. Nuclear power is no longer an unknown new technology.

A large increase in world electricity demand is projected for the coming century. In lieu of endless research programs on "new" concepts, it is now time to proceed vigorously with widespread deployment of the best nuclear power option for which most parameters are already established. Here, we develop an aggressive approach for initiating the deployment of such a system - with the potential to produce over half of the world's electricity by mid-century, and to continue at that level for several centuries.

\section{REACTOR FACTS AND PROJECTIONS}

At late count ${ }^{1} 434$ reactors, each with an average capacity rating of over $800 \mathrm{MWe}$ were in operation in 34 countries. An additional 62 reactors $(\sim 15 \%)$ are under construction or on order. These will have a slightly larger average capacity of $850 \mathrm{MWe}$. Also, 77 reactors are no longer in service and will be decommissioned. On the average, the latter are older, smaller capacity $(\sim 330 \mathrm{MWe})$ reactors. The trend is to build larger reactors and to close down the older, smaller reactors. Almost $80 \%$ of the world's reactors now in operation are light water reactors (LWRs) and almost $75 \%$ of those are pressurized. In the U.S. $100 \%$ of the power reactors are LWRs. Thus, it appears that LWRs are an established technology in the current global nuclear electric power infrastructure.

Nevertheless, there appears to be a small but dominant public perception that nuclear power is unsafe and can lead to the use of nuclear weapons in the future. In consideration of this public perception, those who project future consumption of electricity tend to limit their projections with respect to future nuclear electric capacity and consumption.

* Lawrence Livermore National Laboratory, P.O. Box 808, Livermore, CA 94551 
As a result, there is considerable uncertainty on the future use of nuclear electric power in the U.S. as well as in some other countries. Sweden and Germany have decided to shut down all of their nuclear power reactors in response to political pressure from those opposed to nuclear technology.

The Energy Information Administration (EIA) projects, in its reference case, that U.S. nuclear power capacity in 2020 will be reduced to $58 \%$ of the 1997 value, although because of continuing improvements in operation, the electricity supplied will be down to only $68 \%$. The corresponding projected reductions on a world basis are less severe, $86 \%$ and $94 \%$. These nuclear power projections are made in the context of increased electricity consumption projections in the U.S. and the world of $33 \%$ and $76 \%$, respectively. These data, based on EIA projections ${ }^{2}$ are shown in Table 1. Thus, by the year 2020, the projections in net electricity consumption indicate an average annual increase since 1997 of $1.2 \%$ in the U.S. and $2.5 \%$ in the world.

Increased electricity use is projected throughout this century. Based on composite longer-range projections from various sources, ${ }^{3}$ conservative estimates of electricity consumption during this century are shown in Table 2. An average annual growth rate of $1.4 \%$ is projected for world electricity consumption, thus quadrupling consumption during this century. U.S. electricity consumption is projected to increase at a considerably lower rate, resulting in about $70 \%$ higher consumption by 2100 .

\section{THE NEXT STEP}

With the seemingly ubiquitous and productive LWR technology in place throughout the world, one might assume that only minor advancements in reactor design could be expected. Although design changes appear to be minimal, substantial improvements in advanced LWRs result in even safer and more economical systems than the current fleet. Despite their many desirable features however, advanced LWRs do not provide a sustainable technology. Some advanced LWRs are being built in Japan and in Korea

Table 1. Current and near-term projected nuclear power capacity and consumption and total electric power consumption for the U.S. and the world. ${ }^{2}$

\begin{tabular}{lrrr}
\hline & $\underline{1997}$ & $\underline{2020}$ & $\frac{\text { ratio }^{\text {a }}}{}$ \\
& 99.0 & 57.0 & .58 \\
U.S. nuclear generating capacity, GW & 351.9 & 303.3 & .86 \\
World nuclear generating capacity, GW & 71.8 & 48.7 & .68 \\
U.S. nuclear power consumption, GW & 258.9 & 243.8 & .94 \\
World nuclear power consumption, GW & 72.5 & 85.4 & \\
U.S. nuclear plant capacity factor, \% & 73.6 & 80.4 & \\
World nuclear plant capacity factor, \% & 374 & 497 & 1.33 \\
& 1400 & 2463 & 1.76 \\
U.S. net electricity consumption rate, GW & & & \\
World net electricity consumption rate, GW & 19.2 & 9.8 & \\
U.S. nuclear share of electric consumption, \% & 18.5 & 9.9 & \\
World nuclear share of electric consumption, \% & &
\end{tabular}

${ }^{\text {a }}$ ratio of value in 2020 to value in 1997 
Table 2. Century projections ${ }^{3}$ of annual net electricity consumption rate.

\begin{tabular}{lrrrrr} 
& $\frac{2000}{380}$ & $\frac{2025}{480}$ & $\frac{2050}{560}$ & $\frac{2075}{610}$ & $\frac{2100}{640}$ \\
U.S. net electricity consumption rate, GW & 380 & 2530 & 3570 & 4640 & 6140 \\
World net electricity consumption rate, GW & 1540 & 2530 \\
\hline
\end{tabular}

where public opposition to nuclear technology has not resulted in extended, very costly, construction duration, as was the case in the U.S. with the current fleet of LWRs. Improved licensing procedures for generic advanced LWRs are now available in the U.S. These procedures are meant to eliminate licensing delays and the attendant high construction costs that have occurred previously. Unfortunately, skittish investors have not initiated plans for construction of a nuclear power plant in the U.S. for a quarter century - the new U.S. licensing procedures remain untried.

Without pursuing a program to facilitate the deployment of advanced LWRs in the U.S., the Department of Energy (DOE) has dubbed them Generation III and seemingly dismissed them as contenders in the U.S. DOE considers the advanced LWRs to be insufficiently cost-competitive in a deregulated electricity market, faced with unresolved used fuel disposition plans, and a potential means of nuclear weapon proliferation.

As a result, DOE has launched its Generation IV program, ${ }^{4,5}$ to consider reactor designs and fuel cycles that 1) are even more resistant to nuclear weapon proliferation than the once-through cycle used with LWRs, 2) minimize radioactive material waste and utilize publicly accepted and implemented waste solutions, 3) provide electricity competitively priced with other forms of generation with acceptable risk to capital and having short lead and construction times for new plants, 4) have low likelihood of core damage and no severe damage for plausible initiating events, and 5) meet specified safety criteria. The Generation IV program ${ }^{5}$ envisions research and development (R\&D) on various reactor types such that a prototype plant could be operated by 2020 , and a large scale deployment by 2030 .

It is the thesis of this paper that the exploratory $R \& D$ on various types of new reactor concepts is unnecessary, and in fact incompatible with the large deployment schedule objective. Instead, a program to demonstrate the already highly developed modular fast reactor with fuel recycling should be vigorously pursued. Such a technology is sustainable for centuries. Moreover, it is ethically correct from the standpoint of energy resource conservation and stewardship of residue waste. It can meet all of DOE's Generation IV objectives and would allow beating DOE's target date for large-scale deployment by at least ten years. That should be "The Next Step."

Before examining the status of fast-reactor/fuel-recycling technology and means of initiating its deployment on a large scale, we address the environmental and resource considerations leading to its choice, as well as some issues that are the basis for negative public perception of nuclear power. Public perception needs to be corrected throughout the world to allow global progress on implementation of any nuclear power option.

\section{ENVIRONMENTAL AND RESOURCE CONSIDERATIONS}

Fast reactors with fuel recycling do not require uranium enrichment. Natural uranium would not need to be mined for a very long time. Instead, depleted uranium (two million tons are projected ${ }^{6}$ to be stockpiled at enrichment plants by 2015) would be used as makeup material for new fuel elements. The number of recycles is unlimited, 
therefore discharged fuel is never in need of permanent storage. The waste product from the fuel recycling process can be designed to contain no significant amounts of actinides or long-lived fission products.

Geologic disposal would continue to be desirable for the non-recyclable waste from the fuel recycling process. However, the disposal facility requirements for this waste form would change significantly from those now being considered for used fuel from LWRs. Essentially all the long-lived fission products could be selectively removed in the recycling process (and subsequently transmuted). Waste from fuel recycling would contain no actinides, so there would not be a requirement for long-term safeguards against material diversion. Thus, the time horizon for the geologic disposal site would decrease many thousand to $\sim 500$ years. Such disposal is respectful of future generations.

Systematic retirement of LWRs as they complete their design life and their replacement with fast reactors is an appropriate evolutionary advancement in electric power generation. All of the LWR used fuel would be processed and utilized in new fast reactors. This is the technology that needs to be demonstrated as quickly as possible through construction and operation of a prototype reactor producing power to the grid.

Nuclear power reactors of any type generate electricity without the carbon dioxide emissions released to the atmosphere from fossil fuel power plants. In 1997, carbon emissions from electricity generated ${ }^{7}$ in the U.S. contained $532 \mathrm{Tg} \mathrm{C}$. Had not almost $20 \%$ of the electricity been generated by nuclear plants, another $151 \mathrm{Tg} \mathrm{C}(\sim 28 \%)$ would have been emitted by the additional fossil power plants that would have been required. In view of the concerns about climate change, and the possible contribution to this effect by carbon dioxide in our atmosphere, nuclear power generation has a significant positive effect on the environment.

\section{FISSILE MATERIAL DIVERSION ISSUE}

Both the nuclear weapon and nuclear power communities appear to use the single word "proliferation" or the words "nuclear proliferation" with the implicit understanding that it is in the context of nuclear weapon proliferation and therefore, something to be avoided. On the other hand, proliferation of nuclear power reactors seems to be just what is needed to solve our present and expected future electricity shortages without harming the environment. The word proliferation can signify a good thing! How is the general public to know what is meant if proliferation is used without the intended modifier? The message that the public appears to get is that proliferation of all nuclear technologies is a bad thing.

In any case, the public's concern should not be proliferation of nuclear weapon capability to additional countries. The public's concern should be the potential for diversion of fissile material from its intended use in a power reactor fuel cycle for making nuclear weapons or crude nuclear explosives by individuals that act with or without the approval of the material owner. Thus, it is imperative that fissile materials can nowhere be diverted overtly or clandestinely for the manufacture of nuclear explosives. This can be accomplished with intrinsic physical/chemical characteristics of the technology that is used, together with oversight by international review organizations, such as the International Atomic Energy Agency. The public must not be swayed into a paranoid position precluding peaceful uses of fissile materials and nuclear technology. Nuclear technology offers too many advantages to the health and general well being of humankind and our world environment to ignore. 
Fast reactors with fuel recycling can provide electricity for centuries at a competitive cost in a manner respectful of the environment. Fuel recycling would utilize relatively inexpensive pyro-metallurgical processing and solvent electro-refining. The considerably more expensive aqueous processing previously proposed or used in the nuclear weapon and nuclear power communities was developed to produce pure plutonium. On the other hand, pyro-processing is inherently resistant to material diversion. At no time does pure, separated, plutonium exist. The presence of minor actinides in the plutonium makes it unusable directly for a nuclear explosive, as the actinides produce heat and radiation and preclude, or greatly impede, the construction of an explosive device. Some fission products remain with the plutonium, preventing hands-on theft. Process waste would not contain significant amounts of actinides and therefore, is not at all an attractive material for making nuclear weapons.

\section{USED FUEL/WASTE ISSUE}

The media and even those in the nuclear field use unclear terms relative to various aspects of nuclear technology. Use of inaccurate or ambiguous terms complicates the achievement of public acceptance of nuclear matters. For example, the term "spent nuclear fuel" uses the word nuclear gratuitously, unnecessarily inciting fear in the public. There is no other kind of "spent" fuel making the modifier nuclear necessary. Also, the terms "spent fuel" and "nuclear waste" are often incorrectly used synonymouslyalthough the used fuel from LWRs is barely "spent" in an energy sense and should not be considered to be waste. In the past, less than one percent of the energy potential of mined uranium has been utilized in LWRs.

By whatever name we call used fuel, nuclear technology has advanced to the point that, with the appropriate reactor and fuel design, there should be no used fuel to dispose of in a geologic repository. Only a small amount of radioactive waste with insignificant amounts of actinides and a much reduced half life resulting from the advanced recycling process employed would need to be disposed of in a geologic repository.

\section{RADIATION HEALTH EFFECTS ISSUE}

A critical issue that needs to be resolved in the minds of the public concerns radiation health effects. First, a preponderance of scientific experts in the field must come to agreement. At present there is disagreement among experts regarding the effects of radiation at low levels, below $\sim 50 \mathrm{mSv} / \mathrm{y}$. One group believes that radiation effects are linear and that there is no threshold below which radiation is harmless. A larger group believes that there is a threshold level below which radiation is harmless, and some in this group believe that low-level radiation is in fact beneficial. Clarification of this issue is essential so that unambiguous information can be presented to the public. In view of the scientific discord, the matter has been politicized and even U.S. agencies disagree among themselves.

Resolution in favor of an acceptable threshold will have a positive effect on public attitude regarding nuclear power. Also, the acceptable radiation level that is promulgated must be based on a risk/benefit analysis in the context of other anthropogenic sources. Currently, radiation standards are established far below highly variable natural radiation levels that in the U.S. average $3 \mathrm{mSv} / \mathrm{y}$, and without reference to higher risks from other sources that society now accepts. The unresolved controversy was recently the subject of 
a review by the General Accounting Office. ${ }^{8}$ At present the National Academy of Sciences, through its committee known as BEIR VII (Biological Effects of Ionizing Radiation- No. 7) is reviewing the matter and plans to issue a report next year, but it is doubtful that that schedule will hold. In addition to providing the public with an accepted scientific basis for a radiation standard, considerable savings (reducing the cost of nuclear power) can be realized if the standard is not unnecessarily low.

\section{THE FAST REACTOR SOLUTION}

Fast reactors have been operated successfully at DOE installations for a number of years. Originally, it was thought that fast reactors, while also generating electric power, would be used to produce excess plutonium. The excess pure plutonium and uranium from LWR used fuel would be mixed to provide the necessary fissile content in new mixed oxide (MOX) fuel for LWRs. The nuclear power infrastructure would consist of both fast and thermal reactors and fuel recycling facilities, thus necessitating public transportation of new and used fuel. Exclusive use of fast reactors with on-site fuel recycling, that precludes production of pure plutonium now appears to be the better option.

The Advanced Liquid Metal Reactor (ALMR) program in the U.S. was in full swing and making good progress until 1994. The program goal was to develop a modular fast reactor, sodium cooled, and utilizing metallic fuel elements. The fuel would be recycled at the reactor site using improved pyro-metallurgical and electro-refining processes. Process waste would contain insignificant amounts of actinides and would not be an attractive material diversion target. This program was identified in the 1992 Energy Policy Act as dealing with a key nuclear technology that should be supported with R\&D funding for a five-year period to enable future decisions regarding its course.

Unfortunately, under the negative view of the new Administration beginning in 1993, Congress did not appropriate the necessary funding to support the ALMR program after 1994 and in fact ordered the DOE to terminate the program in February 1994. On February 17, 1993, President Clinton had stated in his first speech ${ }^{9}$ to a joint session of Congress that: "We are eliminating programs that are no longer needed such as nuclear power research and development." The next day, at a public address ${ }^{9}$ in St. Louis, he expanded on his previous evening's talk: "We recommended some unwarranted subsidies be eliminated because the need for the work is much less or nonexistent anymore. For example, we recommended a big cutback in a lot of programs related to the nuclear industry and the elimination of a nuclear research program that is inconsistent with our new energy future." As a result, DOE's ALMR program was cancelled. Work at the Argonne National Laboratory (ANL) on the fuel cycle was suspended, as well as DOEsupported industrial design studies on a commercial power reactor/fuel recycling system by General Electric Co. (GE) and others, such as Burns and Roe.

Fortunately, GE continued its design studies with company funding and with support from Tokyo Electric Power Co. The current reactor design is called Super PRISM. ANL has been able to corroborate some of the fuel processing parameters that make fuel recycling viable. This information was gained as a result of performing some necessary fuel treatment resulting from the directive to shut down the experimental fast reactor in Idaho. As a result, there are sufficient data to proceed with the construction of a demonstration power reactor plant.

The Super PRISM design ${ }^{10-12}$ embodies a number of features that appear to resolve many issues of concern. Particular attention has been given to reactor safety. Passive 
features minimize the need for operator action and expensive backup cooling systems. Considerable savings in the cost of technology demonstration and system hardware are realized because of the modular design. A plant is composed of one to three power blocks, and each power block couples two 1000-MWth fast reactors coupled to a singlesuperheat turbine/generator system producing a net electrical output of $760 \mathrm{MWe}$. Thus a full size plant (six modular reactors) would produce a net output of $2280 \mathrm{MWe}$ at $38 \%$ thermal efficiency. Each module has the ability to operate independently of others. Module size was selected on the basis of constraints on factory fabrication of the reactor/containment vessel.

Although as noted above the trend has been toward higher power LWRs, the modular scaling of Super PRISM is actually cost advantageous. The modular design avoids much field construction effort (reduced field time) in view of extensive factory fabrication, and allows the design to be simplified through the use of passive shutdown heat removal and passive post-accident containment cooling systems. Demonstration of the smaller, but prototypical reactor can be accomplished at reduced cost. The low cost of power also results from the higher capacity factor achieved because of modularity; generic licensing regulations; elimination of active safety systems because enhanced safety is provided by passive features; and simplicity that results in lower operation and maintenance requirements. These features all contribute to the lower cost of electricity.

Super PRISM could be operated with metal or oxide fuel and at a variety of conversion ratios. The fuel cycle using metal fuel and a low conversion ratio minimizes costs. Therefore the demonstration reactor would most likely have metal fuel and operate at a conversion ratio slightly above one (breakeven).

Specifically, it is proposed to demonstrate the operation of a Super PRISM module utilizing its considerable database. A recent economic analysis ${ }^{11}$ of the Super PRISM design indicates that the cost of power, $\$ 28 / \mathrm{MWh}$ for the $\mathrm{n}^{\text {th }}$ of a kind plant, is easily competitive with other types of power. There doesn't appear to be a good reason to conduct exploratory R\&D as proposed in DOE's Generation IV program, referred to earlier, instead of proceeding at once with demonstration of Super PRISM. Some confirmatory R\&D in support of the Super PRISM design would be warranted, however.

\section{NEAR-TERM REACTOR DEMONSTRATION}

At a recent conference, Daniel Fessler, ${ }^{13}$ former Chairman of the California Public Utilities Commission, alluded to an imminent shortage of electric power in Brazil at the end of year 2000 as an example of the worldwide need for clean responsible sources of electricity. He challenged the conference participants to move nuclear power construction out of its apparent hiatus and thus rise to the challenge of the projected worldwide electricity needs. He emphasized the urgency for the nuclear community to proceed on these matters with the comment that "... one shouldn't wait ten weeks to begin a task that must be completed within ten years."

Mr. Fessler's remarks give rise to serious thought and a resulting multifaceted solution to advance the acceptability of nuclear power technology throughout the world. Demonstration of Super PRISM in any country, under international auspices, would be of benefit to all countries. Such a project could be accomplished in Brazil, or in another suitable country, within a ten- to fifteen-year time frame. 


\section{THE BRAZIL DEMONSTRATION VENUE}

Although the fast reactor/fuel recycling demonstration project could technically be conducted anywhere in the world, it would be desirable to perform the demonstration in a developing country, preferably, from a neighborly viewpoint, in the Western Hemisphere. Countries, such as the U.S., France, and Japan, where nuclear power is in relatively wide use, have run into public perception problems regarding new nuclear projects. Although perceptions are changing, the public in these countries does not currently appreciate the need to develop advanced nuclear power plants.

By various measures Brazil is a key world country. It ranks fifth in land area and in population among the world's $\sim 220$ countries. Brazil is a significant generator and consumer of electricity. In 1998, Brazil generated $36.2 \mathrm{GWy}$ of electricity, ranking tenth in electricity generation among world countries. The top ten countries together generated over two-thirds of the world electricity. Over $90 \%$ of Brazil's electricity is hydroelectric. Brazil's per-capita usage will more than double by 2020 according to U.S. projections. ${ }^{2}$ Brazil's population is projected to increase less than $25 \%$ by 2020 . In the same projections, however, electricity consumption is predicted to increase by a factor of 2.8 , carbon emissions by 2.6 , gross domestic product by 2.4 , and total primary energy use by 2.1 .

Until recently, Brazil had only one operating reactor, Angra 1, a 657-MW Westinghouse PWR. Lifetime performance of Angra 1 since its startup in 1982 has suffered. However, its lifetime load factor of only $28.1 \%$ improved to $60.9 \%$ for the year ending June 1999. A second reactor, Angra 2, a 1300-MW Siemens-KWU PWR, was recently completed. It achieved first criticality on July 14, 2000 and 100\% power soon after. Work had been suspended on a third reactor, Angra 3, similar to Angra 2 at the same site. A financial strategy is being developed for continuation of the Angra 3 project that would commence operation in 2006. These two larger units would add $\sim 6 \%$ to the $36.2 \mathrm{GW}$ of electricity generated in Brazil in 1998. Longer-term plans through 2015 include a possible Angra 4 reactor (similar to Angra 2 and 3) and a fifth reactor of an unspecified type. A Super PRISM demonstration project in Brazil is not inconsistent with continuation of those plans, as used fuel from the LWRs could be applied to startup inventories of fast reactors that would most likely be adopted in the future.

Because currently Brazil's electricity is mostly hydroelectric, carbon emissions from electricity generation are practically negligible. In 1990, carbon emissions from electricity generation in Brazil were $0.09 \mathrm{kgC} / \mathrm{Wy}$ compared with $1.54 \mathrm{kgC} / \mathrm{Wy}$ in the U.S. Clearly, Brazil's electricity has not contributed to climate change. But dams are no longer popular in Brazil. Agricultural interests are said to be harmed by further dam construction; rainforests would be flooded thus impacting the world environment; and long distance electricity transmission would be required because of the remote location of the new dams that would be constructed.

Brazil has limited fossil fuel resources. Oil provides primary energy at the rate of 85 $\mathrm{GW}$, with almost $40 \%$ of that imported. Indigenous coal and gas contribute only $\sim 20 \%$ as much primary energy, and ethanol, made from sugar cane, contributes another $\sim 20 \%$. Recently a $3000-\mathrm{km}$ natural gas pipeline, costing \$2B, was built from Bolivia to Brazil. Its current capacity is about 11 billion $\mathrm{m}^{3} / \mathrm{y}$ or about $13 \mathrm{GW}$ of primary energy. If used exclusively for electricity generation in highly efficient combined-cycle gas plants, $7 \mathrm{GW}$ of electricity could be generated, or less than $20 \%$ of the 1998 generation. It should not be assumed, however, that the cost of electricity from such gas plants would be lower than from a Super PRISM plant. 
If the admirable carbon emission performance of Brazil is to continue, new electricity capacity from nuclear and renewable power resources will need to be brought on line to meet the ever-increasing requirement for electric power. A clear solution to Brazil's electricity needs appears to be expanded use of nuclear power. Nuclear power is the leading contender as a future substitute for hydroelectric power, if carbon emissions are to remain low. In view of Brazil's enviable record on carbon emissions from electricity generation, and the projected competitive cost of power through the use of Super PRISM technology there does not appear to be a better solution.

Although Brazil's experience with nuclear technology is limited, they are a signatory of the Nuclear Weapon Non-Proliferation Treaty, have considered development of nuclear powered submarines, have developed isotope enrichment technology, and accept international regulations for safeguards of nuclear material. The initial inventory of fuel for the Super PRISM demonstration reactor could be provided from the used fuel projected to be discharged from Brazil's LWRs by 2010.

Because of Brazil's historically limited nuclear power exposure, demonstration of a fast reactor/ fuel recycle system in Brazil should meet with less public opinion resistance than in countries with a more entrenched anti-nuclear technology sector. Brazil's electricity needs would be met, and also the world public would benefit from the Super PRISM demonstration and its subsequent deployment throughout the world.

\section{PROJECT INITIATION AND MANAGEMENT}

In order to initiate the demonstration, some funding is required to conduct preliminary studies of specific issues, establish the participants, develop a project plan, and secure approvals and funding. A key goal of this initial effort would be to win the genuine interest of the host government (for example, Brazil) in the demonstration project and obtain its permission and facilitating support for conducting the project. The resulting project plan would form the basis for a "full-ahead" direction to proceed. Success of the Super PRISM demonstration is highly dependent on the quality of its leadership. The participants would clearly include a number of industrial and government organizations from throughout the world. Active participation by university personnel and of nuclear technology associations would be encouraged.

The project should be conducted as much as possible on a private business basis in order to avoid government entanglements. Experience gained from this project would benefit various world governments, businesses, and organizations. Because of first-of-akind risks and its global importance, their subsidies should be solicited to defray part of the cost of the Super PRISM demonstration.

\section{IN CONCLUSION}

Although the suggested demonstration project of Super PRISM cannot fill shortterm needs for electricity, an immediate start appears essential. This urgency is dictated by the continuously increasing use of electricity, throughout the world and the global need to maintain low carbon emissions. Every effort should be made to complete the remaining development of the Super PRISM reactor and complete construction of the demonstration reactor by 2015 at the latest to allow wide-scale deployment to be in place by 2030 , consistent with DOE's Generation IV objectives. With an early project start, a qualified management, and dedicated world project team players, such a schedule, needed 
to satisfy future world electricity demands could be met. In fact, it appears that Super PRISM is the only viable technology that can meet the requirements recently set forth by the nine-nation group that includes U.S., Brazil, and Argentina for Generation IV reactors.

The ultimate desired outcome of the Super PRISM demonstration project is adequate, affordable amounts of safe, clean, sustainable electric power throughout this century and beyond for all the world. No more carbon in the atmosphere caused by electricity generation! No more used fuel disposal issues! No more concern about million-year integrity at geologic repositories. No more concern about dwindling energy resources for electricity generation! Multiple replicas of the demonstration reactor and phase-out of fossil-fueled electricity generators would accomplish this purpose.

\section{ACKNOWLEDGEMENTS}

Data on Brazil electricity generation were obtained from various Energy Information Administration sources. Extremely helpful discussions were held with Jose Mauro Esteves dos Santos, Antonio Carlos de O. Barroso, Jorge Spitalnik, and Everton Carvalho, key individuals in Brazil's nuclear energy organizations. However, conclusions about the potential of Brazil as a venue for demonstration of Super PRISM technology are the author's alone.

This work was performed under the auspices of the U.S. Department of Energy by Lawrence Livermore National Laboratory under contract No. W-7405-Eng-48.

\section{REFERENCES}

1. World List of Nuclear Power Plants, Nuclear News, p 35-58, March 2000.

2. International Energy Outlook 2000- With Projections to 2020, Energy Information AdministrationReport, DOER/EIA-0484(2000), March 2000.

3. Walter, Carl E., Directions for Advanced Use of Nuclear Power in Century XXI, Proceedings of American Nuclear Society Global '99 International Conference on Future Nuclear Systems, Jackson Hole, WY, August 30-September 2, 1999.

4. Generation IV: Looking to the Future of Nuclear Power, U.S. Department of Energy, Office of Nuclear Energy, Science, and Technology, January 2000.

5. Discussion on Goals for Generation IV Nuclear Power Systems, from a Workshop held May 1-3, 2000, July 31,2000

6. Lindholm, Ingemar, Depleted Uranium: Valuable Energy Resource or Waste for Disposal?, Uranium Institute 21st Annual Symposium (1996).

7. Annual Energy Outlook 2000- With Projections to 2020, Energy Information Administration Report, DOER/EIA-0383(2000), December 1999.

8. Radiation Standards- Scientific Basis Inconclusive, and EPA and NRC Disagreement Continues, Report to the Honorable Pete Domenici, U.S. Senate, U.S. General Accounting Office, GAO/RCED-00152 , June 2000.

9. Feb 17, 181993 speeches: http://www.whitehouse.gov/library/index.html.

10. Boardman, Charles E., et al, A Description of the S-PRISM Plant, Paper 8168, Proceedings of ICONE 8, $8^{\text {th }}$ International Conference on Nuclear Engineering, Baltimore, MD, April 2-6, 2000.

11. Boardman, Charles E., Allen. E. Dubberley, and Marvin Hui, Optimizing the Size of the Super PRISM Reactor, Paper 8003, Proceedings of ICONE 8, $8^{\text {th }}$ International Conference on Nuclear Engineering, Baltimore, MD, April 2-6, 2000.

12. Dubberley, A. E., C. E. Boardman, K. Yoshida, T. Wu, Super PRISM Oxide and Metal Fuel Designs, Paper 8002, Proceedings of ICONE 8, $8^{\text {th }}$ International Conference on Nuclear Engineering, Baltimore, MD, April 2-6, 2000.

13. Fessler, Daniel, Concluding plenary talk at the American Nuclear Society's Global ' 99 Conference on Nuclear Technology- Bridging the Millennia, Jackson Hole, WY, September 2, 1999. 